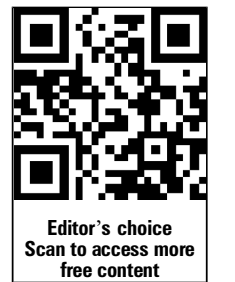

free content
Alcohol Epidemiologic Data System, CSR Incorporated, Arlington, Virginia, USA

\section{Correspondence to} Dr Young-Hee Yoon, Alcohol Epidemiologic Data System, CSR, Incorporated, 2107 Wilson Blvd., Suite 1000, Arlington, VA 22201, USA; yhyoon@csrincorporated.com.

Received 13 December 2012 Revised 14 April 2013 Accepted 29 April 2013 Published Online First 24 May 2013
To cite: Yoon $\mathrm{Y}$-H, Chen $\mathrm{CM}, \mathrm{Yi}$ H-Y. Inj Prev 2014;20:21-28.

\title{
Unintentional alcohol and drug poisoning in association with substance use disorders and mood and anxiety disorders: results from the 2010 Nationwide Inpatient Sample
}

\author{
Young-Hee Yoon, Chiung M Chen, Hsiao-Ye Yi
}

\begin{abstract}
Objective To examine unintentional alcohol and drug poisoning in association with substance use disorders (SUDs) and mood and anxiety disorders.

Method International Classification of Diseases, Ninth Revision, Clinical Modification (ICD-9-CM) externalcause-of-injury codes on discharge records of patients ages 12+ years from the 2010 Nationwide Inpatient Sample were examined to identify cases with unintentional alcohol poisoning (E860) and/or drug poisoning (E850-E858). ICD-9-CM diagnosis codes were examined to identify comorbid alcohol dependence, drug dependence, tobacco use disorder, and mood/anxiety disorders. Poisson regression was used to derive risk ratios to assess the associations between these comorbid conditions and alcohol/drug poisoning.
\end{abstract}

Results Estimated numbers of hospitalisations related to unintentional alcohol and drug poisoning were, respectively, 5623 and 60423 in men, and 3147 and 68568 in women. For both sexes, the proportion with SUDs or mood/anxiety disorders was significantly higher among inpatients with alcohol and drug poisoning than among all inpatients. Estimated risk ratios indicated strong relationships of SUDs and mood/ anxiety disorders with unintentional poisoning from alcohol and drugs.

The strongest association was between alcohol dependence and alcohol poisoning for both sexes. Significant associations also existed between drug dependence and drug poisoning, and mood/anxiety disorders and poisoning from alcohol and drugs. Conclusions SUDs and mood/anxiety disorders are key risk factors for unintentional poisoning by alcohol and drugs among inpatients in the USA. Effective treatments of these disorders should be targeted as poisoning prevention efforts. Future studies are needed to clarify a potential bias in the data due to differential inpatient mental condition screening practices.

\section{INTRODUCTION}

Poisoning death rates have increased significantly in the USA, nearly tripling from $4.8 / 100000$ population in 1980 to $13.5 / 100000$ in 2008 . The public health implication of this increase is even greater when compared with motor vehicle traffic death rates, which decreased by almost a half from 22.9/ 100000 to $12.5 / 100000$ during the same period. ${ }^{1}$ In 2009, unintentional poisoning became the second leading cause of unintentional injury deaths, after motor vehicle crashes. Notably, most poisoning deaths were unintentional, ${ }^{2}$ and over $90 \%$ of fatal poisoning cases were from drugs and alcohol. The increase in unintentional poisoning fatalities was largely from prescription opioids and benzodiazepines. ${ }^{3}$

Research has indicated that acute poisoning occurs mainly as a consequence of substance use disorders (SUDs), ${ }^{4} 5$ which often co-occur with mood and anxiety disorders. ${ }^{6-11}$ Moreover, individuals with mood and anxiety disorders are likely to be prescribed with high doses of opioids or other psychotropic medications. ${ }^{12}$ Some studies have found SUDs and mental disorders common among drug poisoning decedents. ${ }^{13-15}$ Individuals with SUDs or in mental distress had increased risk for unintentional poisoning. ${ }^{16-18}$

To date, little nationally representative data exist on associations between drug poisoning and psychiatric disorders among non-fatal cases. Studies that have examined these associations often ignored alcohol involvement, although studies of poisoning fatalities have found a high co-occurrence of alcohol and drug use among poisoning decedents, ${ }^{14}{ }^{19-21}$ as well as elevated risk of poisoning fatality from pharmacological interaction of concurrent use of alcohol and illicit or prescription drugs. ${ }^{22-25}$ The current study's objective is to use nationally representative hospitalisation data to examine (1) associations of unintentional alcohol and drug poisoning with SUDs and mood and anxiety disorders; and (2) potential gender differences in these associations.

\section{METHODS}

\section{Data sources}

This study uses data from the 2010 Nationwide Inpatient Sample (NIS), the largest all-payer inpatient-care database in the USA. The NIS is part of the Healthcare Cost and Utilisation Project sponsored by the Agency for Healthcare Research and Quality of the US Department of Health and Human Services. In 2010, 45 States (comprising over $96 \%$ of the US population) participated in the NIS, which included 7.8 million records of hospital discharges from 1051 hospitals, approximately a $20 \%$ stratified sample of all US community hospitals. ${ }^{26}$

\section{Case identification}

In the 2010 NIS, each patient discharge record contains up to 25 diagnoses based on the International Classification of Diseases, Ninth Revision, Clinical Modification (ICD-9-CM). Each also contains up to four ICD-9-CM 
external-cause-of-injury codes (E-codes), which record the mechanism (eg, motor-vehicle or drug poisoning) and intent (ie, intentional or unintentional) of the injury. In ICD-9-CM E-codes, alcohol poisoning can only be coded as 'unintentional,' while drug poisonings can be 'unintentional,' 'intentional,' or 'intent undetermined.' Table 1 lists the ICD-9-CM codes used in our analysis. We searched all-listed E-codes to identify all cases with unintentional alcohol poisoning (E860) and/or unintentional drug poisoning (E850-E858), except those with co-occurring suicide or self-inflicted injuries (E950-E959). We also used diagnosis codes to help identify poisoning by specific type of drugs, because many unintentional patients with drugpoisoning were poisoned from more than four drugs. For cases with multiple poisoning diagnoses, if some diagnoses had no associated E-codes, the intent of these diagnoses was determined through available E-codes on the same discharge record. We used all-listed diagnosis codes to identify comorbid psychiatric disorders, including alcohol dependence syndrome, drug dependence, tobacco use disorder, as well as bipolar, depressive and anxiety disorders.

Because mental disorders comorbid with SUDs or unintentional alcohol and drug poisoning were rare among children, we excluded patients under age 12 years. Our study sample included 6686905 remaining discharges (excluding $0.12 \%$ cases without valid reports of sex). Of these, 1757 cases had a diagnosis of unintentional alcohol poisoning, and 25792 had a diagnosis of unintentional drug poisoning. Among these, we further identified three mutually exclusive groups: (1) unintentional alcohol poisoning only (996 alcohol poisoning cases without any co-occurring drug poisoning); (2) unintentional drug poisoning only (24 893 drug poisoning cases without any co-occurring alcohol poisoning); and (3) unintentional poisoning by alcohol and drugs (648 cases). Unintentional drug poisoning was further classified into nine categories by specific drug. These include eight psychoactive drug categories-illicit opioids $(\mathrm{N}=2838)$, prescription opioids $(\mathrm{N}=6769)$, non-opioid analgesics $(\mathrm{N}=3217)$, sedatives and hypnotics $(\mathrm{N}=2242)$, tranquilisers $(\mathrm{N}=5436)$, antidepressants $(\mathrm{N}=1152)$, other psychotropic agents $(\mathrm{N}=3973)$ and other drugs acting on the central nervous system $(\mathrm{N}=2350)$ - and one 'other drugs' category (antibiotics, anti-infectives and all other drugs) $(\mathrm{N}=6531)$ (see table 1 for detail).

\section{Statistical analysis}

To produce nationally representative estimates, we analysed data using SAS (V.9.2, SAS Institute Inc, Cary, North Carolina, USA), a statistical software capable of handling the stratified sampling design of NIS and incorporating discharge weights into its procedures. Descriptive estimates are presented along with their 95\% CIs. Cross-tabulation was used to examine how SUDs and mood and anxiety disorders were distributed across unintentional alcohol and/or drug poisoning and all hospitalisations. The strength of associations between alcohol/drug poisoning and psychiatric disorders was further quantified by the adjusted prevalence ratio (or risk ratio (RR)) of cases with a particular type of psychiatric disorder to those without it, estimated from three Poisson regression models. In these models, the dependent variable was the three dichotomous poisoning outcomes: unintentional alcohol poisoning only, unintentional drug poisoning only, and unintentional alcohol and drug poisoning, with no alcohol or drug poisoning as the base group. The covariates in the models included patient's age, race, primary payer, census region, location of residence and median income of patient's ZIP Code. Similarly, eight Poisson regression models-corresponding to the eight categories of specific drugs, with 'other drugs' as the base category in each model-were used to

Table 1 International Classification of Diseases, Ninth Revision, Clinical Modification (ICD-9-CM) codes used in this study

\begin{tabular}{|c|c|}
\hline Description & ICD-9-CM codes \\
\hline \multicolumn{2}{|l|}{ Poisoning-related diagnoses } \\
\hline Unintentional alcohol poisoning & E860 \\
\hline Unintentional drug poisoning & E850-E858 \\
\hline Illicit opioids (including opium and heroin) & $\operatorname{E} 850.0(965.00,965.01)^{*}$ \\
\hline Prescription opioids (including methadone, and other opiates and related narcotics) & E850.1-E850.2 $(965.02,965.09)^{*}$ \\
\hline Non-opioid analgesics & E850.3-E850.9 (965.1-965.9)* \\
\hline Sedatives/hypnotics (including barbiturates) & $\mathrm{E} 851-\mathrm{E} 852,967^{*}$ \\
\hline Tranquilisers (including benzodiazepines) & E853 $(969.1-969.5)^{*}$ \\
\hline Antidepressants & E854.0, 969.0* \\
\hline Other psychotropic agents & E854.1-E854.8 (969.6-969.9)* \\
\hline Drugs acting on central and autonomic nervous system & $\operatorname{E} 855(966,968,971)^{*}$ \\
\hline Other drugs (antibiotics, other anti-infectives and all other drugst) & E856-E858 $(960-964,972-979)^{*}$ \\
\hline \multicolumn{2}{|l|}{ Substance use disorder-related diagnoses } \\
\hline Alcohol dependence syndrome & $303.0-303.9$ \\
\hline Drug dependence & $304.0-304.9$ \\
\hline Tobacco use disorder & 305.1 \\
\hline \multicolumn{2}{|l|}{ Mood and anxiety disorder-related diagnoses } \\
\hline Bipolar disorders & 296.0-296.1, 296.4-296.9 \\
\hline Depressive disorders & 293.83, 296.2, 296.3, 300.4, 311 \\
\hline Anxiety disorder & $\begin{array}{l}\text { 293.84, 300.0-300.3, 300.5, 300.89, 300.9, 308, 309.81, } 313 \\
\text { (minus } 313.23,313.81,313.89,313.9 \text { ) }\end{array}$ \\
\hline
\end{tabular}


compare relative risk associated with specific psychiatric disorders for being poisoned by specific types of drugs among cases with any unintentional drug poisoning. The 'other drugs' category is the base category, because these drugs are mainly used to treat physiological symptoms. This contrasts with the eight psychoactive drug categories mainly for treating mental disorders or pain-drugs more subject to abuse, more potentially addictive, and most relevant to the disorders our study focuses on. These models included an additional covariate, multidrug poisoning, dummy-coded for more than one type of drug poisoning. To detect potential gender differences, all results were obtained for men and women separately.

\section{RESULTS}

As shown in table 2, in 2010, the estimated number of hospitalisations related to unintentional alcohol poisoning was 5623 in men and 3147 in women. The estimated number of hospitalisations related to unintentional drug poisoning was 60423 in men and 68568 in women. Half of hospitalisations with drug poisoning resulted from prescription opioids, sedatives and hypnotics, tranquilisers and antidepressants for men and women.

\section{Prevalence of SUDs and mood and anxiety disorders among unintentional alcohol poisoning-related and drug poisoning-related hospitalisations}

Table 3 shows that the proportion of men with any diagnosis of SUDs and mood and anxiety disorders was about twice as high in alcohol-poisoning and drug-poisoning cases as in all hospitalisations. Among women, the difference was even larger. The prevalence of alcohol dependence was significantly higher among alcohol poisoning-related hospitalisations $(52.5 \%$ and $39.5 \%$ for men and women, respectively) than among drug poisoning-related ones, whereas prevalence of drug dependence was significantly higher among drug poisoning-related hospitalisations (13.5\% and $10.6 \%$ for men and women, respectively) than among alcohol-poisoning ones. For mood and anxiety disorders, prevalence across the three poisoning groups was more similar and always much higher than that among all hospitalisations, regardless of sex.

For patients hospitalised with alcohol and drug poisoning, the pattern of distribution for SUDs and mood and anxiety disorders was more similar to that in alcohol-poisoning cases than in drug-poisoning cases.

\section{Associations of SUDs and mood and anxiety disorders with unintentional alcohol-poisoning and drug-poisoning hospitalisations}

Table 4 shows that adjusted RRs were greater than 1 and statistically significant for most SUDs and mood and anxiety disorders, suggesting strong relationships of SUDs and mood and anxiety disorders with hospitalisations for unintentional poisoning from alcohol and drugs. Patients with alcohol dependence were significantly more likely to be hospitalised for alcohol poisoning alone than those without alcohol dependence (RR 13.16, 95\% CI 12.18 to 14.23 for men and RR 30.18, 95\% CI 26.51 to 34.36 for women). Alcohol dependence also had a strong, albeit smaller, association with poisoning from alcohol and drugs (RR 3.39, 95\% CI 3.02 to 3.81 for men and RR $8.16,95 \%$ CI 7.11 to 9.36 for women). Note that the RRs of alcohol dependence for alcohol poisoning only as well as for poisoning from alcohol and drugs among women was more than double that among men. Similarly, although smaller, a significant association existed between drug dependence and drug poisoning (RR 2.94, 95\% CI 2.86 to 3.02 for men and RR $3.80,95 \%$ CI 3.70 to 3.91 for women).

Compared with RRs for SUDs, RRs for mood and anxiety disorders generally were somewhat smaller. However, patients with mood and anxiety disorders were more likely to be hospitalised for drug poisoning than for alcohol poisoning. Bipolar disorder had a stronger association with drug poisoning (RR 2.09, 95\% CI 2.03 to 2.15 for men and RR 3.53, 95\% CI 3.44 to 3.62 for women) than depressive or anxiety disorders, whereas depressive disorder had a stronger association with alcohol poisoning (RR 1.51, 95\% CI 1.39 to 1.65 for men and

Table 2 Estimated number of hospitalisations related to unintentional poisoning by alcohol and drug for patients aged 12 years or older, Nationwide Inpatient Sample, USA, 2010

\begin{tabular}{|c|c|c|c|c|}
\hline \multirow[b]{2}{*}{ Hospitalisations with } & \multicolumn{2}{|l|}{ Male } & \multicolumn{2}{|l|}{ Female } \\
\hline & $\mathbf{N}$ & Estimated number (95\% Cl) & N & Estimated number $(95 \% \mathrm{Cl})$ \\
\hline Unintentional alcohol poisoning & 1125 & 5623 (4316 to 6930$)$ & 632 & 3147 (2558 to 3735$)$ \\
\hline Unintentional alcohol poisoning only* & 687 & 3426 (2344 to 4509$)$ & 309 & 1540 (1108 to 1973) \\
\hline Unintentional drug poisoning & 12063 & 60423 (55181 to 65666) & 13729 & 68568 (64284 to 72851$)$ \\
\hline Unintentional drug poisoning only $\dagger$ & 11550 & 57853 (52823 to 62883$)$ & 13343 & 66648 (62489 to 70807$)$ \\
\hline Unintentional poisoning by alcohol and drug $\ddagger$ & 367 & 1841 (1537 to 2144$)$ & 281 & 1394 (1167 to 1620$)$ \\
\hline \multicolumn{5}{|l|}{ Unintentional poisoning by specific drugs } \\
\hline Illicit opioid & 1475 & 7399 (6528 to 8269) & 1363 & 6834 (6106 to 7561$)$ \\
\hline Prescription opioid & 3051 & 15206 (13903 to 16508$)$ & 3718 & 18520 (17172 to 19868$)$ \\
\hline Non-opioid analgesics & 1181 & 5881 (5333 to 6429) & 2036 & 10156 (9340 to 10971) \\
\hline Sedatives/hypnotics & 843 & 4200 (3788 to 4612$)$ & 1399 & 6941 (6353 to 7529$)$ \\
\hline Tranquilisers & 2427 & 12121 (11054 to 13187$)$ & 3009 & 15015 (13865 to 16165$)$ \\
\hline Antidepressants & 429 & 2129 (1880 to 2378$)$ & 723 & 3571 (3196 to 3945) \\
\hline Other psychotropic agents & 2514 & 12777 (9567 to 15987$)$ & 1459 & 7378 (5905 to 8850$)$ \\
\hline Drugs acting on central and autonomic nervous system & 1108 & 5511 (4933 to 6089) & 1242 & 6186 (5673 to 6699$)$ \\
\hline Other drugs (antibiotics, other anti- infectives and all other drugs) & 2924 & $14588(13616$ to 15561$)$ & 3607 & 18004 (16896 to 19111) \\
\hline Total hospital discharges & 2715067 & 13605452 (13067549 to 14143354$)$ & 3971838 & 19844133 (19097199 to 20591067) \\
\hline
\end{tabular}


Table 3 Percentage of hospitalisations with any diagnosis of substance use disorders and mood and anxiety disorders, by unintentional alcohol and drug poisoning status, for patients aged 12 years or older, Nationwide Inpatient Sample, USA, 2010

\begin{tabular}{|c|c|c|c|c|}
\hline \multirow[b]{2}{*}{$\begin{array}{l}\text { Substance use disorders and mood } \\
\text { and anxiety disorders }\end{array}$} & \multicolumn{4}{|l|}{ Hospitalisations } \\
\hline & $\begin{array}{l}\text { All } \\
\%(95 \% \mathrm{Cl})\end{array}$ & $\begin{array}{l}\text { Unintentional alcohol } \\
\text { poisoning only* } \\
\%(95 \% \mathrm{Cl})\end{array}$ & $\begin{array}{l}\text { Unintentional drug } \\
\text { poisoning onlyt } \\
\%(95 \% \mathrm{Cl})\end{array}$ & $\begin{array}{l}\text { Unintentional poisoning } \\
\text { by alcohol and drug } \\
\%(95 \% \mathrm{Cl})\end{array}$ \\
\hline \multicolumn{5}{|l|}{ Male } \\
\hline \multicolumn{5}{|l|}{ Substance use disorder } \\
\hline Alcohol dependence & 5.3 (4.9 to 5.7$)$ & 52.5 (38.5 to 66.4$)$ & $8.0(7.2$ to 8.7$)$ & 25.4 (20.6 to 30.1$)$ \\
\hline Drug dependence & 2.6 (2.2 to 3.0$)$ & $5.5(1.5$ to 9.5$)$ & 13.5 (11.8 to 15.2$)$ & 7.4 (4.6 to 10.2$)$ \\
\hline Tobacco use disorder & 17.7 (17.0 to 18.3$)$ & 33.4 (24.9 to 41.8$)$ & 31.5 (29.8 to 33.2$)$ & 33.8 (28.8 to 38.9$)$ \\
\hline Any of the above disorders & 21.9 (21.1 to 22.7$)$ & $62.5(47.5$ to 77.5$)$ & $42.5(40.4$ to 44.5$)$ & $52.4(47.0$ to 57.8$)$ \\
\hline \multicolumn{5}{|l|}{ Mood and anxiety disorder } \\
\hline Bipolar disorder & 3.5 (3.3 to 3.7$)$ & 6.8 (4.0 to 9.7$)$ & 10.8 (10.1 to 11.4$)$ & 12.3 (9.0 to 15.7$)$ \\
\hline Depressive disorder & 10.0 (9.7 to 10.4$)$ & 21.5 (16.4 to 26.6$)$ & $18.6(17.5$ to 19.7$)$ & $21.0(16.3$ to 25.6$)$ \\
\hline Anxiety disorder & 5.0 (4.8 to 5.1$)$ & $6.4(4.2$ to 8.5$)$ & 9.7 (8.9 to 10.5$)$ & $11.7(8.5$ to 14.9$)$ \\
\hline Any of the above disorders & $16.9(16.3$ to 17.4$)$ & $31.3(24.5$ to 38.2$)$ & 34.8 (33.4 to 36.3 ) & 38.1 (32.0 to 44.2 ) \\
\hline Any mental or substance use disorder & 32.9 (32.0 to 33.7$)$ & 69.1 (55.0 to 83.2 ) & 59.2 (57.6 to 60.8$)$ & $67.6(62.6$ to 72.5$)$ \\
\hline \multicolumn{5}{|l|}{ Female } \\
\hline \multicolumn{5}{|l|}{ Substance use disorder } \\
\hline Alcohol dependence & 1.4 (1.3 to 1.5$)$ & 39.5 (28.6 to 50.4$)$ & 3.7 (3.3 to 4.0$)$ & 26.6 (21.1 to 32.2$)$ \\
\hline Drug dependence & $1.4(1.3$ to 1.5$)$ & $4.5(0.2$ to 8.9$)$ & 10.6 (9.7 to 11.6$)$ & $8.8(5.6$ to 12.1$)$ \\
\hline Tobacco use disorder & 10.1 (9.7 to 10.5$)$ & $29.6(21.3$ to 37.9$)$ & 26.5 (25.2 to 27.9$)$ & 39.1 (33.3 to 44.9$)$ \\
\hline Any of the above disorders & $11.7(11.2$ to 12.1$)$ & 53.3 (40.0 to 66.6$)$ & 34.6 (33.2 to 36.1$)$ & $58.2(52.2$ to 64.2$)$ \\
\hline \multicolumn{5}{|l|}{ Mood and anxiety disorder } \\
\hline Bipolar disorder & 3.5 (3.3 to 3.7$)$ & $10.0(6.3$ to 13.7$)$ & $14.1(13.3$ to 14.8$)$ & 15.9 (11.7 to 20.1$)$ \\
\hline Depressive disorder & $13.1(12.7$ to 13.5$)$ & $30.0(22.5$ to 37.5$)$ & 29.2 (28.0 to 30.4$)$ & 33.3 (27.5 to 39.1$)$ \\
\hline Anxiety disorder & 6.7 (6.4 to 6.9$)$ & 12.7 (7.8 to 17.6$)$ & $13.8(13.0$ to 14.6$)$ & 11.7 (8.0 to 15.4 ) \\
\hline Any of the above disorders & 20.9 (20.3 to 21.5$)$ & 44.0 (34.2 to 53.9$)$ & 49.5 (48.1 to 51.0$)$ & 55.4 (49.4 to 61.4$)$ \\
\hline Any mental or substance use disorder & 27.7 (27.0 to 28.5$)$ & 66.8 (54.0 to 79.5$)$ & $62.9(61.5$ to 64.3$)$ & $81.0(76.0$ to 86.0$)$ \\
\hline
\end{tabular}

Table 4 Adjusted risk ratios (RR) † for unintentional poisoning by alcohol and drugs among hospitalisations of patients aged 12 years or older, Nationwide Inpatient Sample, USA, 2010

\begin{tabular}{|c|c|c|c|c|c|c|c|c|c|}
\hline \multirow{2}{*}{$\begin{array}{l}\text { Substance use disorders and mood } \\
\text { and anxiety disorders }\end{array}$} & \multicolumn{3}{|c|}{$\begin{array}{l}\text { Unintentional alcohol poisoning } \\
\text { only versus no alcohol/drug } \\
\text { poisoning }\end{array}$} & \multicolumn{3}{|c|}{$\begin{array}{l}\text { Unintentional drug poisoning } \\
\text { only versus no alcohol/drug } \\
\text { poisoning }\end{array}$} & \multicolumn{3}{|c|}{$\begin{array}{l}\text { Unintentional poisoning by } \\
\text { alcohol and drug versus no } \\
\text { alcohol/drug poisoning }\end{array}$} \\
\hline & RR & & $95 \% \mathrm{Cl}$ & RR & & $95 \% \mathrm{Cl}$ & RR & & $95 \% \mathrm{Cl}$ \\
\hline \multicolumn{10}{|l|}{ Male } \\
\hline \multicolumn{10}{|l|}{ Substance use disorder } \\
\hline Alcohol dependence & 13.16 & *** & 12.18 to 14.23 & 0.71 & $* * *$ & 0.69 to 0.74 & 3.39 & $* * *$ & 3.02 to 3.81 \\
\hline Drug dependence & 0.44 & *** & 0.37 to 0.51 & 2.94 & $* * *$ & 2.86 to 3.02 & 0.90 & & 0.75 to 1.08 \\
\hline Tobacco use disorder & 1.04 & & 0.96 to 1.12 & 1.44 & $* * *$ & 1.41 to 1.46 & 1.14 & * & 1.03 to 1.26 \\
\hline \multicolumn{10}{|l|}{ Mood and anxiety disorder } \\
\hline Bipolar disorder & 0.96 & & 0.83 to 1.10 & 2.09 & $* * *$ & 2.03 to 2.15 & 2.02 & $* * *$ & 1.74 to 2.35 \\
\hline Depressive disorder & 1.51 & *** & 1.39 to 1.65 & 1.86 & $* * *$ & 1.82 to 1.90 & 1.87 & $* * *$ & 1.66 to 2.11 \\
\hline Anxiety disorder & 0.88 & & 0.76 to 1.01 & 1.39 & $* * *$ & 1.35 to 1.43 & 1.50 & *** & 1.29 to 1.73 \\
\hline \multicolumn{10}{|l|}{ Female } \\
\hline \multicolumn{10}{|l|}{ Substance use disorder } \\
\hline Alcohol dependence & 30.18 & $* * *$ & 26.51 to 34.36 & 0.82 & $* * *$ & 0.79 to 0.86 & 8.16 & $* * *$ & 7.11 to 9.36 \\
\hline Drug dependence & 0.41 & $* * *$ & 0.32 to 0.53 & 3.80 & $* * *$ & 3.70 to 3.91 & 1.23 & * & 1.01 to 1.50 \\
\hline Tobacco use disorder & 1.49 & $* * *$ & 1.32 to 1.69 & 1.81 & $* * *$ & 1.77 to 1.84 & 2.21 & $* * *$ & 1.96 to 2.49 \\
\hline \multicolumn{10}{|l|}{ Mood and anxiety disorder } \\
\hline Bipolar disorder & 1.35 & $* *$ & 1.12 to 1.61 & 3.53 & $* * *$ & 3.44 to 3.62 & 3.03 & $* * *$ & 2.57 to 3.57 \\
\hline Depressive disorder & 1.93 & $* * *$ & 1.70 to 2.18 & 2.51 & $* * *$ & 2.47 to 2.56 & 2.83 & $* * *$ & 2.50 to 3.21 \\
\hline Anxiety disorder & 1.18 & * & 1.01 to 1.38 & 1.34 & $* * *$ & 1.31 to 1.37 & 0.90 & & 0.77 to 1.07 \\
\hline
\end{tabular}

tEstimated from Poisson regression adjusting for patient's age, race, primary payer, census region, location of residence, and median income of patient's ZIP Code.

${ }^{* * *} p<0.001 ;{ }^{* *} p<0.01 ;{ }^{*} p<0.05$. 
RR 1.93, 95\% CI 1.70 to 2.18 for women), regardless of sex. For men, only the RR of depressive disorder was greater than 1 for alcohol poisoning, but the RRs of all three mood and anxiety disorders were greater than 1 for drug poisoning and poisoning from alcohol and drugs. For women, mood and anxiety disorders had strong and positive effects on all three poisoning categories, except for anxiety disorder on the combined poisoning category. Generally, the effect of SUDs and mood and anxiety disorders was stronger for women than for men.

Associations of SUDs and mood and anxiety disorders with unintentional poisoning hospitalisation by specific drug Table 5 presents RRs estimated from eight Poisson regression models, adjusting for the same covariates as in table 4, plus alcohol and multidrug poisoning. Each of these models used

Table 5 Adjusted risk ratios (RR) † for poisoning by specific drugs versus other drug poisoning among unintentional drug poisoning related hospitalisations of patients aged 12 years or older, Nationwide Inpatient Sample, USA, 2010

\begin{tabular}{|c|c|c|c|c|c|c|c|c|c|c|c|c|}
\hline \multirow{3}{*}{$\begin{array}{l}\text { Substance use disorders and } \\
\text { mood and anxiety disorders }\end{array}$} & \multicolumn{12}{|c|}{ Unintentional poisoning by } \\
\hline & \multicolumn{3}{|c|}{ Illicit opioid } & \multicolumn{3}{|c|}{ Prescription opioids } & \multicolumn{3}{|c|}{ Non-opioid analgesics } & \multicolumn{3}{|c|}{ Sedatives and hypnotics } \\
\hline & RR & & $95 \% \mathrm{Cl}$ & RR & & $95 \% \mathrm{Cl}$ & RR & & $95 \% \mathrm{Cl}$ & RR & & $95 \% \mathrm{Cl}$ \\
\hline \multicolumn{13}{|l|}{ Male } \\
\hline Alcohol dependence & 0.91 & * & 0.83 to 0.99 & 0.89 & $* * *$ & 0.83 to 0.95 & 1.17 & $* * *$ & 1.07 to 1.27 & 0.88 & * & 0.78 to 0.99 \\
\hline Drug dependence & 1.90 & $* * *$ & 1.80 to 2.01 & 1.48 & *** & 1.42 to 1.54 & 1.22 & *** & 1.12 to 1.33 & 1.34 & *** & 1.21 to 1.49 \\
\hline Tobacco use disorder & 1.19 & $* * *$ & 1.14 to 1.26 & 1.14 & $* * *$ & 1.10 to 1.19 & 1.29 & $* * *$ & 1.22 to 1.36 & 1.10 & * & 1.02 to 1.18 \\
\hline Bipolar disorder & 0.94 & & 0.87 to 1.02 & 0.99 & & 0.94 to 1.05 & 1.08 & & 0.99 to 1.18 & 1.46 & *** & 1.32 to 1.61 \\
\hline Depressive disorder & 1.04 & & 0.98 to 1.11 & 1.10 & $* * *$ & 1.05 to 1.15 & 1.22 & $* * *$ & 1.15 to 1.30 & 1.47 & $* * *$ & 1.36 to 1.58 \\
\hline Anxiety disorder & 0.95 & & 0.88 to 1.03 & 1.02 & & 0.97 to 1.08 & 0.95 & & 0.87 to 1.04 & 1.22 & $* * *$ & 1.11 to 1.34 \\
\hline Alcohol poisoning & 1.10 & & 0.97 to 1.25 & 1.10 & & 1.00 to 1.22 & 0.96 & & 0.82 to 1.12 & 1.44 & $* * *$ & 1.21 to 1.71 \\
\hline \multirow[t]{3}{*}{ Multidrug poisoning } & 1.59 & $* * *$ & 1.52 to 1.67 & 1.43 & *** & 1.39 to 1.48 & 1.30 & $* * *$ & 1.23 to 1.37 & 1.65 & $* * *$ & 1.55 to 1.76 \\
\hline & \multicolumn{3}{|c|}{ Tranquilisers } & \multicolumn{3}{|c|}{ Antidepressants } & \multicolumn{3}{|c|}{ Other psychotropic agents } & \multicolumn{3}{|c|}{ Nervous system } \\
\hline & RR & & $95 \% \mathrm{Cl}$ & RR & & $95 \% \mathrm{Cl}$ & RR & & $95 \% \mathrm{Cl}$ & $\mathrm{RR}$ & & $95 \% \mathrm{Cl}$ \\
\hline Alcohol dependence & 1.08 & * & 1.01 to 1.15 & 1.21 & ** & 1.05 to 1.39 & 1.01 & & 0.95 to 1.07 & 1.08 & & 0.98 to 1.19 \\
\hline Drug dependence & 1.20 & $* * *$ & 1.14 to 1.26 & 1.09 & & 0.95 to 1.25 & 1.29 & $* * *$ & 1.23 to 1.35 & 1.03 & & 0.93 to 1.13 \\
\hline Tobacco use disorder & 1.08 & $* * *$ & 1.04 to 1.12 & 1.03 & & 0.94 to 1.14 & 1.23 & $* * *$ & 1.19 to 1.28 & 1.21 & $* * *$ & 1.14 to 1.29 \\
\hline Bipolar disorder & 1.41 & $* * *$ & 1.34 to 1.49 & 2.79 & *** & 2.46 to 3.17 & 1.21 & $* * *$ & 1.14 to 1.28 & 1.43 & $* * *$ & 1.32 to 1.55 \\
\hline Depressive disorder & 1.32 & $* * *$ & 1.27 to 1.38 & 2.82 & $* * *$ & 2.56 to 3.12 & 0.91 & $* * *$ & 0.86 to 0.96 & 1.01 & & 0.94 to 1.09 \\
\hline Anxiety disorder & 1.24 & $* * *$ & 1.18 to 1.31 & 1.09 & & 0.96 to 1.24 & 1.05 & & 0.98 to 1.12 & 0.98 & & 0.89 to 1.08 \\
\hline Alcohol poisoning & 1.27 & *** & 1.17 to 1.39 & 1.12 & & 0.88 to 1.42 & 1.34 & *** & 1.23 to 1.46 & 0.83 & & 0.69 to 1.01 \\
\hline Multidrug poisoning & 2.08 & *** & 2.00 to 2.16 & 2.99 & $* * *$ & 2.73 to 3.27 & 1.34 & $* * *$ & 1.29 to 1.39 & 1.71 & $* * *$ & 1.62 to 1.81 \\
\hline & \multicolumn{12}{|c|}{ Unintentional poisoning by } \\
\hline \multirow{2}{*}{$\begin{array}{l}\text { Substance use disorders and } \\
\text { mood and anxiety disorders }\end{array}$} & \multicolumn{3}{|c|}{ Illicit opioid } & \multicolumn{3}{|c|}{ Prescription opioids } & \multicolumn{3}{|c|}{ Non-opioid analgesics } & \multicolumn{3}{|c|}{ Sedatives and hypnotics } \\
\hline & $\mathrm{RR}$ & & $95 \% \mathrm{Cl}$ & RR & & $95 \% \mathrm{Cl}$ & RR & & $95 \% \mathrm{Cl}$ & RR & & $95 \% \mathrm{Cl}$ \\
\hline \multicolumn{13}{|l|}{ Female } \\
\hline Alcohol dependence & 1.07 & & 0.96 to 1.20 & 0.93 & & 0.86 to 1.01 & 1.29 & *** & 1.18 to 1.40 & 0.79 & $* *$ & 0.68 to 0.93 \\
\hline Drug dependence & 1.92 & $* * *$ & 1.81 to 2.05 & 1.50 & $* * *$ & 1.44 to 1.56 & 1.26 & $* * *$ & 1.18 to 1.36 & 1.60 & $* * *$ & 1.48 to 1.74 \\
\hline Tobacco use disorder & 1.41 & $* * *$ & 1.34 to 1.49 & 1.22 & $* * *$ & 1.18 to 1.26 & 1.19 & $* * *$ & 1.14 to 1.25 & 1.09 & $* *$ & 1.03 to 1.16 \\
\hline Bipolar disorder & 1.00 & & 0.93 to 1.08 & 1.05 & * & 1.01 to 1.10 & 1.01 & & 0.95 to 1.08 & 1.19 & $* * *$ & 1.10 to 1.29 \\
\hline Depressive disorder & 1.06 & * & 1.00 to 1.12 & 1.12 & $* * *$ & 1.08 to 1.15 & 1.18 & $* * *$ & 1.13 to 1.23 & 1.43 & $* * *$ & 1.36 to 1.51 \\
\hline Anxiety disorder & 0.96 & & 0.90 to 1.03 & 1.01 & & 0.97 to 1.06 & 0.99 & & 0.94 to 1.05 & 1.02 & & 0.95 to 1.09 \\
\hline Alcohol poisoning & 1.15 & & 0.98 to 1.35 & 1.08 & & 0.96 to 1.21 & 1.00 & & 0.86 to 1.16 & 1.13 & & 0.94 to 1.37 \\
\hline \multirow[t]{3}{*}{ Multidrug poisoning } & 1.81 & *** & 1.72 to 1.90 & 1.40 & $* * *$ & 1.35 to 1.44 & 1.36 & $* * *$ & 1.30 to 1.41 & 1.58 & *** & 1.50 to 1.66 \\
\hline & \multicolumn{3}{|c|}{ Tranquilisers } & Antid & oressa & & Othe & sycho & pic agents & Nervc & S syste & \\
\hline & RR & & $95 \% \mathrm{Cl}$ & $\mathbf{R R}$ & & $95 \% \mathrm{Cl}$ & RR & & $95 \% \mathrm{Cl}$ & RR & & $95 \% \mathrm{Cl}$ \\
\hline Alcohol dependence & 1.14 & *** & 1.06 to 1.22 & 1.31 & $* * *$ & 1.14 to 1.52 & 0.95 & & 0.85 to 1.06 & 1.00 & & 0.87 to 1.15 \\
\hline Drug dependence & 1.26 & $* * *$ & 1.20 to 1.32 & 1.20 & $* *$ & 1.06 to 1.36 & 1.47 & $* * *$ & 1.38 to 1.56 & 1.33 & $* * *$ & 1.21 to 1.45 \\
\hline Tobacco use disorder & 1.17 & *** & 1.12 to 1.21 & 1.16 & $* * *$ & 1.07 to 1.25 & 1.39 & *** & 1.32 to 1.46 & 1.28 & $* * *$ & 1.20 to 1.35 \\
\hline Bipolar disorder & 1.51 & *** & 1.45 to 1.58 & 2.03 & $* * *$ & 1.84 to 2.24 & 1.29 & $* * *$ & 1.22 to 1.37 & 1.27 & *** & 1.18 to 1.37 \\
\hline Depressive disorder & 1.40 & $* * *$ & 1.35 to 1.45 & 2.18 & $* * *$ & 2.02 to 2.36 & 0.94 & * & 0.88 to 0.99 & 1.09 & $* *$ & 1.02 to 1.16 \\
\hline Anxiety disorder & 1.24 & *** & 1.19 to 1.29 & 1.09 & & 0.99 to 1.19 & 0.92 & * & 0.85 to 0.99 & 0.99 & & 0.92 to 1.07 \\
\hline Alcohol poisoning & 1.36 & $* * *$ & 1.26 to 1.48 & 1.49 & $* * *$ & 1.23 to 1.79 & 1.34 & $* * *$ & 1.17 to 1.53 & 0.82 & & 0.66 to 1.02 \\
\hline Multidrug poisoning & 2.11 & $* * *$ & 2.04 to 2.18 & 3.02 & $* * *$ & 2.82 to 3.24 & 1.48 & *** & 1.41 to 1.55 & 2.03 & $* * *$ & 1.93 to 2.13 \\
\hline
\end{tabular}


poisoning by a specific drug category versus poisoning by 'other drugs' as the dependent variable.

Overall, about two-thirds of the adjusted RRs are greater than 1 and statistically significant, suggesting a strong and positive effect of SUDs, mood and anxiety disorders, alcohol poisoning and multidrug poisoning on poisoning from specific drugs versus poisoning from other drugs.

The effects of alcohol dependence on unintentional poisoning by non-opioid analgesics, tranquilisers and antidepressants were positive regardless of sex. Patients with drug dependence or tobacco use disorder generally were also more likely to have unintentional poisoning from the specific drugs than from other drugs, with few exceptions. Thus, there was no significant effect of drug dependence on poisoning by antidepressants or nervous system drugs and no significant effect of tobacco use disorder on poisoning by antidepressants among men.

Overall, associations between mood and anxiety disorders and unintentional poisoning by specific drugs were quite similar to that for SUDs, except that mood and anxiety disorder patients were no more likely to have poisoning by illicit opioids than patients without those disorders. For men and women, bipolar disorder was associated with a marked increase in prevalence of unintentional poisoning by sedatives and hypnotics, psychotropic agents and drugs affecting the nervous system; depressive disorder was associated with increased risks for unintentional poisoning by prescription opioids, non-opioid analgesics, sedatives and hypnotics, tranquilisers and antidepressants. For women, bipolar disorder was also associated with poisoning by prescription opioids, and depressive disorder was associated with poisoning by drugs affecting the nervous system. Anxiety disorder was associated with increased risks for unintentional poisoning by sedatives and hypnotics as well as tranquilisers for men, but only with that of tranquilisers for women.

In men, the RRs of alcohol poisoning were significantly greater than 1 for poisoning by sedatives/hypnotics, tranquilisers and other psychotropic agents, whereas in women they were significant only for poisoning by psychotropic agents (ie, tranquilisers, antidepressants and other psychotropic agents). The RR of multidrug poisoning was greater than 1 and statistically significant for all eight drug categories, with the largest for poisoning by antidepressants and tranquilisers.

\section{DISCUSSION}

This study is among the first to provide population-based evidence from a nationally representative sample of hospital records to establish SUDs and mood and anxiety disorders as key risk factors for unintentional poisoning by alcohol and different classes of drugs among US inpatients. Notably, we found that prevalence of SUDs and mood and anxiety disorders was much higher in patients with alcohol and/or drug poisoning than in patients without any alcohol or drug poisoning. Adjusted for sociodemographic characteristics, alcohol dependence was a strong predictor for alcohol poisoning and poisoning from combined use of alcohol and drugs, and, to a lesser degree, drug dependence was a predictor for drug. Similarly, mood and anxiety disorders increased risk for alcohol and drug poisoning. While previous studies have similarly identified SUDs and mental health as risk factors for drug poisoning among special subpopulations, such as veterans, ${ }^{13}$ women of reproductive age, ${ }^{27}{ }^{28}$ and illicit drug users, ${ }^{16-18}$ the current study furthers these observations to establish this relationship in the general population.

Our results indicate that alcohol dependence poses a much greater risk for alcohol poisoning among women than among men. This is consistent with the literature on gender differences in alcohol metabolism. In particular, women achieve higher blood alcohol concentrations and become more impaired than men after drinking equivalent amounts of alcohol. ${ }^{29}$ This likely puts alcohol-dependent women at greater risk for alcohol poisoning. Women are also more exposed to psychoactive medications than men, ${ }^{30} 31$ and therefore at higher risk for alcohol-drug interactions. Among patients hospitalised with alcohol dependence and alcohol poisoning, a larger proportion of women than men were also poisoned by psychotropic drugs, particularly benzodiazepine-based tranquilisers (data not shown).

Our findings also suggest that morbidity risk varies across poisoning by specific drugs for individuals with SUDs and mood and anxiety disorders. In particular, patients with mood or anxiety disorders were at higher risk for poisoning by medications intended to treat their respective mental health problems, such as sedatives and hypnotics, tranquilisers, antidepressants, other psychotropic agents, and drugs affecting the central and autonomic nervous system. Although our analyses do not shed light on why patients with mood or anxiety disorders are more likely to be poisoned by the medicines intended to treat their conditions, we offer three possible explanations. First, Motjabai and Olfson ${ }^{32}$ reported that multiple medication use involving antidepressant and antipsychotic medications has significantly increased, although some combinations have unproven efficacy in clinical trials. These trends put patients at increased risk of drug-drug interactions with uncertain gains for quality of care and clinical outcomes. Second, lack of compliance among some patients with mental-disorder with pharmacotherapy guidelines can result in excessive intake of medications. ${ }^{33}$ Some studies show that patients with bipolar disorder are particularly poor at following pharmacotherapeutic guidelines. ${ }^{34}$ Third, previous studies have shown that SUDs and mental disorders are frequently associated with physical pain. Many physicians now prescribe opioid painkillers more liberally to treat non-cancer-related pain. Furthermore, patients with mental illness are more often prescribed higher dosages of opioids in combination with benzodiazepines in addition to antidepressants and other psychotropic medications. ${ }^{12} 36$ Combining multiple central nervous system-depressant drugs, including alcohol, tends to increase risk for substance-related poisoning, which is consistent with our study's observations.

A major strength of this study is its use of nationally representative hospital data to explicate complexity in poisoning cases. Nevertheless, there are some limitations inherent with the data. The threshold level for poisoning by various substances cannot be identified from the data; hospital records in NIS do not contain laboratory results on blood alcohol or drug concentrations that caused poisoning. Because pharmacological interaction of alcohol with drugs can induce poisoning at lower dosages, using alcohol poisoning instead of more broadly defined alcohol involvement may underestimate the effect of alcohol on drug poisoning. Moreover, our analysis included only poisoning cases clearly indicated as unintentional by E-codes and likely underestimates all unintentional poisoning cases. There is a substantial proportion of alcohol poisoning and drug poisoning cases $(24.8 \%$ and $17.8 \%$, respectively) in which the intentionality cannot be identified by associated E-codes on their records (ie, cases with intent coded as undetermined or without associated E-codes at all). For a sensitivity test, we treated all these cases (except those with suicide/homicide codes on their records) as unintentional poisoning cases and included them in the analyses. The results (data not shown) presented patterns similar to those reported in tables 3-5. 
Therefore, excluding these cases did not seem to cause biases in the findings. Finally, due to the cross-sectional nature of the data, we cannot rule out the possibility that someone hospitalised for alcohol poisoning may be more likely to be screened for alcohol dependence than someone hospitalised for other reasons. This potential confounding effect may result in an overestimation in the observed relationships. Future studies (eg, using samples with known inpatient mental condition screening practices) are needed to assess this potential bias in our findings. Traditionally, poisoning has been perceived as a toxicology issue, and treatment has focused mostly on physiological symptoms unless there is an indication of self-harm. ${ }^{37}$ However, our study shows that even unintentional poisoning is significantly related to comorbidity with SUDs and/or mood and anxiety disorders. Because mental patients are at higher risk for recidivism of unintentional injuries, ${ }^{38}$ integrated treatments of physiological and mental problems should be recommended for patients with alcohol-poisoning and/or drug-poisoning. Moreover, contrary to popular belief that poisoning is a mere consequence of acute heavy alcohol or drug use, our findings suggest that poisoning is more a consequence of chronic SUDs and mood and anxiety disorders. Therefore, effective treatment of mental illness and/ or SUDs should be targeted as poisoning prevention. Our findings also underscore the importance of providing patients with clear instructions for taking their medications and informing them about heightened poisoning risk from alcohol-and-drug and drug-and-drug interactions.

\section{What is already known on the subject}

- A few studies of special subpopulation groups (eg, patients treated in Veterans Health Administration facilities) or state medical examiner records (eg, decedents in West Virginia) have found that substance use disorders (SUDs) and mental disorders were common among individuals who died of drug poisoning.

- These studies also suggested that individuals with an SUD or mental distress are at increased risk for experiencing unintentional poisoning. However, these relationships have not been examined in general population-based studies.

\section{What this study adds}

- This is the first population-based study to establish SUDs and mood and anxiety disorders as key risk factors for unintentional poisoning by alcohol and different types of drugs among inpatients in the USA.

- This study provides evidence that patients with mood or anxiety disorders were at higher risk for unintentional poisoning by medications that were intended to treat their respective mental health problems, such as sedatives and hypnotics, tranquilisers, antidepressants, other psychotropic agents and drugs affecting the central nervous system.

- The findings point to the need for integrated healthcare services for medical and mental problems in the treatment of patients with unintentional alcohol and/or drug poisoning.

Contributors All authors have contributed significantly to the preparation of this manuscript, including participation in designing the study, analysing and interpreting the data, drafting the manuscript and approving the final draft being submitted. The views and opinions expressed in this article are those of the authors and should not be construed to represent the views of the sponsoring agency or the Federal Government.

Funding This article is based on a study conducted for the Alcohol Epidemiologic Data System project funded by the National Institute on Alcohol Abuse and Alcoholism, National Institutes of Health through Contract No.

HHSN267200800023C to CSR, Incorporated.

Competing interests None.

Provenance and peer review Not commissioned; externally peer reviewed.

\section{REFERENCES}

1 Warner M, Chen LH, Makuc DM, et al. Drug poisoning deaths in the United States, 1980-2008. NCHS Data Brief 2011;81:1-8.

2 Bohnert AS, Fudalej $S$, Ilgen MA. Increasing poisoning mortality rates in the United States, 1999-2006. Public Health Rep 2010;125:542-7.

3 Paulozzi LJ, Weisler RH, Patkar AA. A national epidemic of unintentional prescription opioid overdose deaths: how physicians can help control it. J Clin Psychiatry 2011;72:589-92.

4 Bjornaas MA, Teige B, Hovda KE, et al. Fatal poisonings in Oslo: a one-year observational study. BMC Emerg Med 2010;10:13.

5 Lahti RA, Vuori E. Fatal alcohol poisoning: medico-legal practices and mortality statistics. Forensic Sci Int 2002;126:203-9.

6 Conway KP, Compton W, Stinson FS, et al. Lifetime comorbidity of DSM-IV mood and anxiety disorders and specific drug use disorders: results from the National Epidemiologic Survey on Alcohol and Related Conditions. I Clin Psychiatry 2006;67:247-57.

7 Kessler RC, Berglund P, Demler O, et al. Lifetime prevalence and age-of-onset distributions of DSM-IV disorders in the National Comorbidity Survey Replication. Arch Gen Psychiatry 2005;62:593-602. Erratum in: Arch Gen Psychiatry 2005:62:768. Merikangas, Kathleen R [added]

8 Grant BF, Stinson FS, Hasin DS, et al. Prevalence, correlates, and comorbidity of bipolar I disorder and axis I and II disorders: results from the National Epidemiologic Survey on Alcohol and Related Conditions. J Clin Psychiatry 2005:66:1205-15.

9 Quello SB, Brady KT, Sonne SC. Mood disorders and substance use disorder: a complex comorbidity. Sci Pract Perspect 2005;3:13-21.

10 Martins SS, Fenton MC, Keyes KM, et al. Mood and anxiety disorders and their association with non-medical prescription opioid use and prescription opioid-use disorder: longitudinal evidence from the National Epidemiologic Study on Alcohol and Related Conditions. Psychol Med 2012;42:1261-72.

11 Swendsen JD, Merikangas KR. The comorbidity of depression and substance use disorders. Clin Psychol Rev 2000;20:173-89.

12 Braden JB, Sullivan MD, Ray GT, et al. Trends in long-term opioid therapy for noncancer pain among persons with a history of depression. Gen Hosp Psychiatry 2009:31:564-70

13 Bohnert AS, Ilgen MA, Ignacio RV, et al. Risk of death from accidental overdose associated with psychiatric and substance use disorders. Am J Psychiatry 2012;169:64-70. Erratum in: Am J Psychiatry 2012;169:99.

14 Hall AJ, Logan JE, Toblin RL, et al. Patterns of abuse among unintentional pharmaceutical overdose fatalities. JAMA 2008;300:2613-20.

15 Toblin RL, Paulozzi LJ, Logan JE, et al. Mental illness and psychotropic drug use among prescription drug overdose deaths: a medical examiner chart review. J Clin Psychiatry 2010;7:491-6.

16 Darke S, Ross J, Hall W. Overdose among heroin users in Sydney, Australia: I. Prevalence and correlates of non-fatal overdose. Addiction 1996;91:405-11.

17 Galea S, Nandi A, Coffin PO, et al. Heroin and cocaine dependence and the risk of accidental non-fatal drug overdose. J Addict Dis 2006;25:79-87.

18 Tobin KE, Latkin CA. The relationship between depressive symptoms and nonfatal overdose among a sample of drug users in Baltimore, Maryland. J Urban Health 2003:80:220-9.

19 Coffin PO, Galea S, Ahern J, et al. Opiates, cocaine and alcohol combinations in accidental drug overdose deaths in New York City, 1990-98. Addiction 2003:98:739-47.

20 Shah NG, Lathrop SL, Reichard RR, et al. Unintentional drug overdose death trends in New Mexico, USA, 1990-2005: combinations of heroin, cocaine, prescription opioids and alcohol. Addiction 2008;103:126-36.

21 Yoon $\mathrm{YH}$, Stinson FS, Yi H, et al. Accidental alcohol poisoning mortality in the United States, 1996-1998. Alcohol Res Health 2003;27:110-18.

22 McCance-Katz EF, Kosten TR, Jatlow P. Concurrent use of cocaine and alcohol is more potent and potentially more toxic than use of either alone-a multiple-dose study. Biol Psychiatry 1998;44:250-9.

23 Koski A, Vuori E, Ojanperä I. Relation of postmortem blood alcohol and drug concentrations in fatal poisonings involving amitriptyline, propoxyphene and promazine. Hum Exp Toxicol 2005:24:389-96. 
24 Schiødt FV, Lee WM, Bondesen S, et al. Influence of acute and chronic alcohol intake on the clinical course and outcome in acetaminophen overdose. Aliment Pharmacol Ther 2002;16:707-15.

25 Weathermon R, Crabb DW. Alcohol and medication interactions. Alcohol Res Health 1999:23:40-54.

26 HCUP. Introduction to the HCUP Nationwide Inpatient Sample (NIS) 2010. Rockville, MD: Agency for Health Research and Quality, 2012.

27 Cox S, Kuo C, Jamieson DJ, et al. Poisoning hospitalisations among reproductive-aged women in the USA, 1998-2006. Inj Prev 2011;17:332-7.

28 McClure CK, Katz KD, Patrick TE, et al. The epidemiology of acute poisonings in women of reproductive age and during pregnancy, California, 2000-2004. Matern Child Health J 2011:15:964-73.

29 Taylor JL, Dolhert N, Friedman L, et al. Alcohol elimination and simulator performance of male and female aviators: a preliminary report. Aviat Space Environ Med 1996:67:407-13.

30 Center for Substance Abuse Treatment. Substance Abuse Treatment: Addressing the Specific Needs of Women. Treatment Improvement Protocol (TIP) Series 51. HHS Publication No. (SMA) 09-4426. Rockville, MD: Substance Abuse and Mental Health Services Administration, 2009.

31 Davis K. Use and expenses for prescribed psychotherapeutics, by subclass, 2009: estimates for the U.S. civilian noninstitutionalized population. Statistical Brief \#386. Rockville, MD: Agency for Healthcare Research and Quality, 2012. http://www. meps.ahrq.gov/mepsweb/data files/publications/st386/stat386.pdf (accessed 28 Feb 2013)

32 Mojtabai R, Olfson M. National trends in psychotropic medication polypharmacy in office-based psychiatry. Arch Gen Psychiatry 2010;67:26-36.

33 Webster LR, Cochella S, Dasgupta N, et al. An analysis of the root causes for opioid-related overdose deaths in the United States. Pain Med 2011;12(Suppl 2): S26-35.

34 Sajatovic M, Ignacio RV, West JA, et al. Predictors of nonadherence among individuals with bipolar disorder receiving treatment in a community mental health clinic. Compr Psychiatry 2009;50:100-7.

35 Weiss RD, Greenfield SF, Najavits LM, et al. Medication compliance among patients with bipolar disorder and substance use disorder. J Clin Psychiatry 1998;59:172-74.

36 Sullivan MD, Edlund MJ, Zhang $\mathrm{L}$, et al. Association between mental health disorders, problem drug use, and regular prescription opioid use. Arch Intern Med 2006;166:2087-93.

37 Greene SL, Dargan PI, Jones AL. Acute poisoning: understanding $90 \%$ of cases in a nutshell. Postgrad Med J 2005;81:204-16.

38 Wan JJ, Morabito DJ, Khaw L, et al. Mental illness as an independent risk factor for unintentional injury and injury recidivism. J Trauma 2006;61:1299-304.

39 Commission on Professional and Hospital Activities. The international classification of diseases, ninth revision, clinical modification. Michigan, Ann Arbor, 1978.

\section{Injury prevention in Tajikistan}

WHO/Europe is assisting the ministry of health of Tajikistan to address various causes of injury. This includes a policy dialogue on road safety and a train-the-trainer course. Based on a special module of the TEACH-VIP curriculum. The programme trained teachers in the health sector, traumatologists, police officers, NGOs and governmental representatives.

\section{Fall prevention exercise programmes reduce serious injuries}

A $B M J$ review of 17 studies testing the effectiveness of exercise programmes for the elderly found that they resulted in a significantly lower risk of suffering an injury after a fall. The trials involved several exercise routines, including Tai Chi and gait, balance exercises and often strength and resistance components. Compared with the control groups, those in exercise programmes had a $37 \%$ reduced rate of injuries from falls, a $43 \%$ rate of severe injuries and a $61 \%$ reduction in fractures. The successes were mostly attributed to improvements in balance, reaction time and coordination and possibly improvements in bone mass.

\section{Utah celebrates 30-year-old injury prevention programme}

When Utah's department of health established an injury prevention programme, it was then one of the first five in the USA. The department recently celebrated the 30th anniversary of this programme. The initial focus was on children and later included suicides and abuse. A recent triumph was the $62 \%$ decline in teens dying in crashes since graduated driving licensing was enacted in 1999. 